\title{
An additive manufacturing fabricated a split Pitot tube transducer for mechanical ventilator analyzers
}

\author{
Luiz A. K. de Andrade ${ }^{1}$ • Elisangela F. Manffra ${ }^{1}$
}

Received: 2 July 2020 / Accepted: 22 December 2020 / Published online: 2 January 2021

(C) Sociedade Brasileira de Engenharia Biomedica 2021

\begin{abstract}
Introduction Frequent calibration of ventilators and anesthesia machines might reduce the risk of death and of sequelae in patients under mechanical ventilation. However, ventilator analyzers might be difficult to purchase due to high cost or even in trade-restrictive scenarios, such as the COVID-19 pandemic. To alleviate this problem, the aim of this article is to present the design and characterization of a Pitot tube transducer fabricated with additive manufacturing (AM), to be used in ventilator analyzers.

Method A split Pitot tube (SPT) transducer was designed using computer-aided design (CAD) and characterized using finite element method (FEM) simulations. Bernoulli's equation was used to determine a transducer discharge coefficient. The sensor was fabricated with the acrylonitrile butadiene styrene (ABS) thermoplastic, with the fused deposition modeling after properly configuring the $3 \mathrm{D}$ printer.

Results According to the simulated velocity profile, the transducer does not impose excessive resistance to the flow and the pressure profile revealed that the pressure is constant and stable inside the pressure lines. The characteristic curve of differential pressure (dP) versus flow is quadratic. For the minimal and maximal simulated flows 0.01 to $300 \mathrm{~L} / \mathrm{min}$, the corresponding $\mathrm{dP}$ values are $6.535 \cdot 10^{-4} \mathrm{~Pa}$ and $13.178 \cdot 10^{3} \mathrm{~Pa}$.

Conclusion The split Pitot tube transducer developed here has appropriate characteristics for measuring air flows from mechanical ventilators, and the delivered pressures can be read by commercial electronic sensors. The AM is viable for fabricating the transducer, and the printing time is considerably low compared to that necessary to order a similar part from a sales representative.
\end{abstract}

Keywords Pitot tube $\cdot$ Flow transducer $\cdot$ Simulation $\cdot$ Additive manufacturing $\cdot$ Fused deposition modeling

\section{Introduction}

It is well known that malfunction in mechanical ventilation might put patients at risk of death, prolonged recovery times, or development of sequelae. Among the possible causes for critical incidents with patients under ventilators are equipment failures which correspond to a small, but not negligible part of incidents (Cooper et al. 1984, Cassidy et al. 2011). It has been shown that the presence of clinical engineers (CE) in the staff of hospitals mitigates the risks related to mechanical ventilators because they might collaborate with the health professionals as well as perform in-house evaluation and repairs

Elisangela F. Manffra

elisangela.manffra@pucpr.br

1 Graduate Program in Health Technology, Pontifícia Universidade Católica do Paraná, Rua Imaculada Conceição 1155,

Curitiba 80215-901, Brazil speeding up the processes (Yoshioka et al. 2014; Hossain et al. 2016). To do this, the CE should have access to proper ventilator analyzers (Yoshioka et al. 2014) which might be challenging. In order to mitigate patient risk due to mechanical ventilator failures, it would be important to expand the access of $\mathrm{CE}$ to proper equipment.

Actually, maintenance operations are critically impacted by the access to equipment and parts whenever demand occurs, and reduction of downtime costs is critical (Khajavi et al. 2014; Yeong and Chua 2013) especially in developing countries (Hossain et al. 2016). The situation is worse in a pandemic trade-restrictive scenario (Martin-Noguerol et al. 2020) when it is difficult to purchase parts of ventilators and of analyzers. A possible way to alleviate this problem is the development of cheaper and more accessible equipment worldwide. This work intends to contribute in this sense, by presenting a flow transducer possible to use in ventilator analyzers. 
The flow transducer is a critical part of the analyzers because it allows measuring the tidal volume by integrating the flow delivered per unit time (Badnjevic et al. 2017). Among the possible types of flow transducers, those based on Pitot tubes are particularly interesting because they exhibit lower flow resistance and cheaper implementation in comparison to variable-orifice flow, orifice flow, and Fleish-type meters, for instance (Bridgeman et al. 2012). Moreover, the modified Pitot tubes can measure very low air velocities and can be used to detect tidal volumes of infants and children (Wolf and Volgyesi 1995).

In order to allow the access to this critical part wherever and whenever it is needed, we established that our transducer should be suitable for fabricating with an additive manufacturing (AM) method. Introduced as rapid prototyping (RP) and three-dimensional (3D) printing, the AM technology was originally devised for producing prototypes (Gibson et al. 2015; Khajavi et al. 2014) but it is now used to produce final functional parts of biomedical devices, such as hearing aids and prosthesis. Different from milling or cutting apart from a block of material, AM builds up the part, usually layer upon layer, using powders, liquid, or filaments and, consequently, produces much less waste (Dizon et al. 2018). This method has been recognized as particularly important during the COVID-19 outbreak when 3D printing has been used to produce personal protective equipment and devices for patient's support such as venturi valves and ventilation adaptors (Martin-Noguerol et al. 2020).

In summary, the aim of this article is to present the design and characterization of a Pitot tube transducer possible to be fabricated with AM. This paper is organized as follows: In "Method," we describe the design of the Pitot transducer, the simulations for obtaining its relevant characteristics, and the fabrication method. In "Results," we present the simulated velocity and pressure profiles as well as the fabricated transducer. Finally, we compare the characteristics of our transducer with others discussing its potential relevance and conclude providing future perspectives on the basis of the achieved results.

\section{Method}

\section{Design of the Pitot transducer}

The SPT transducer was designed using the CAD software SolidWorks (SolidWorks 2020). The initial project considered characteristics such as the possibility to fabricate by AM 3D printing and pressure sensitivity. Our choice for the AM process was the fused deposition modeling (FDM) due to its open and simple technology which allows the use of thermoplastics with specific properties (Ngo et al. 2018). Due to some issues in printing hollow structures, it was necessary to establish the position of a stability plane to avoid nonuniform printing.

Figure 1a shows where the inlet gas flow from the exterior meets the pressure sensing orifice, which conducts the pressure signal through the pressure line. The inlet flow continues through a passage below the pressure sensing point. For the sake of production, the sensor was split into two parts: one for the inlet flow (Fig. 1a) and the other for the outlet flow (Fig. 1b). They only differ regarding the flow directions in which the pressure is measured.

This design allows a bidirectional flow measurement. These two parts (inlet and outlet) are attached to each other with nuts and bolts. An O-ring seal is used between these parts to avoid air leaks by contact; the increase in the gas pressure inside the tube, the better is the sealing. No lubricant is needed in the surfaces contacting the O-ring because the parts do not move relative to each other (Parker 1997).

The length of the transducer is $85 \mathrm{~mm}$ and its internal and external diameters are $14 \mathrm{~mm}$ and $23 \mathrm{~mm}$, respectively. The front view of the split part (Fig. 2) shows the bolts and nuts for fixing the transducer's flanges as well as the pressure sensing orifice and the discharge area.

\section{Flow transducer discharge simulation}

A discharge flow was simulated through the finite element method (FEM) using the COMSOL Multiphysics software simulator and the built-in libraries (COMSOL 2020) with a tetrahedral mesh and extra-fine elements. Only the flow volume was considered in the simulation and the mesh model is shown in Fig. 3. It was possible to use a simplified mesh model due to the symmetry axis, reducing the computational effort by a half. The fluid considered in the simulations was air and the flow velocity was considered 0 in the transducer's walls, by default.

A laminar fluid flow was simulated using the NavierStokes (1) and continuity (2) equations for a compressible flow, using the Laminar Flow Library of the COMSOL software.

$\rho \frac{D \vec{V}}{D t}=-\nabla p+\rho \vec{g}+\mu \nabla^{2} \vec{V}$

$\nabla \cdot \vec{V}=0$

where $\mathrm{g}$ is the acceleration of gravity, $V$ is the flow velocity, $p$ is the pressure, $\rho$ is the fluid density $\left(1.2041 \mathrm{~kg} / \mathrm{m}^{3}\right.$ for air), and $\mu$ is the fluid viscosity $\left(1.85 \cdot 10^{-5} \mathrm{~Pa} \mathrm{~s}\right.$ for air). For simulations, different values of inlet flow and a constant outlet pressure ( $0 \mathrm{kPa}$ over absolute atmospheric pressure) were established. As result of these simulations, the velocity profile and the differential pressure ( $\mathrm{dP}$ ) between inlet and outlet lines were obtained. 


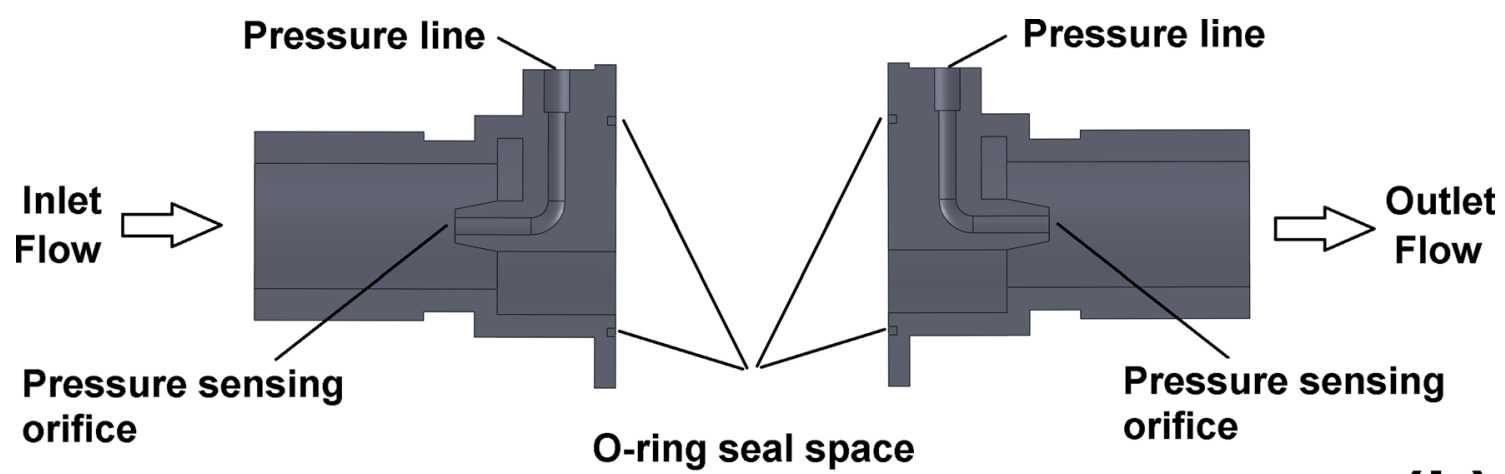

(a)

(b)

Fig. 1 Inlet flow transducer (a) and outlet flow transducer (b). The pressure signal is conducted from the sensing orifice to the pressure line. An O-ring seal is used between these parts to avoid air leaks

\section{Bernoulli and discharge equations}

The Bernoulli equation (3) defines the relationship between the fluid velocity, the fluid pressure, and the height above some fixed point for a fluid flowing through a pipe with a variable cross-sectional area. The equation is the starting point for understanding the principle of the $\mathrm{dP}$ flow meter (Thorn et al. 1999).

$\frac{P 1}{\rho g}+\frac{V 1^{2}}{2 g}+h 1=\frac{P 2}{\rho g}+\frac{V 2^{2}}{2 g}+h 2$

where $P 1$ and $P 2$ are the fluid pressures at two distinct sites, $V 1$ and $V 2$ are fluid velocities at these sites, $\rho$ is the fluid density, and $g$ is the acceleration of gravity. Considering no height differences $(h 1=h 2)$ and $V 1=0 \mathrm{~m} / \mathrm{s}$ at intake pressure sensing line, it is possible to isolate the $\mathrm{dP}$ :

$\Delta P=P 1-P 2=\frac{1}{2} \rho V 2^{2}$

With the flow channel sectional area $A_{\mathrm{c}}$ and the flow velocity $V$, it is possible to obtain the flow $Q$ :

$Q=C_{\mathrm{d}} A_{\mathrm{c}} V$ where $C_{\mathrm{d}}$ is the discharge coefficient, defined as the ratio between the actual and theoretical flow (Meriläinen et al. 1993), which depends on the ratio between the channel area and the total area of the tube and on the Reynolds number, $R_{\mathrm{e}}$, defined by:

$R_{\mathrm{e}}=V D \frac{\rho}{\mu}$

where $\mu$ corresponds to the gas viscosity, $V$ to the velocity, and $D$ to the tube diameter. Finally, it is possible to obtain the flow $Q$ combining Eqs. (7), (8), and (9):

$Q=C_{\mathrm{d}} A_{\mathrm{c}} \sqrt{\frac{2 \Delta P}{\rho}}$

where:

$C_{\mathrm{d}}=C_{\mathrm{d}}(Q, \rho, \mu)$

and,

$\rho=\rho\left(\rho_{0}, P_{\mathrm{AW}}, T\right)$
Fig. 2 Front view of the transducer. The pressure sensing orifice and the discharge area are shown as well as the positions of the bolt and nuts on the transducer flange

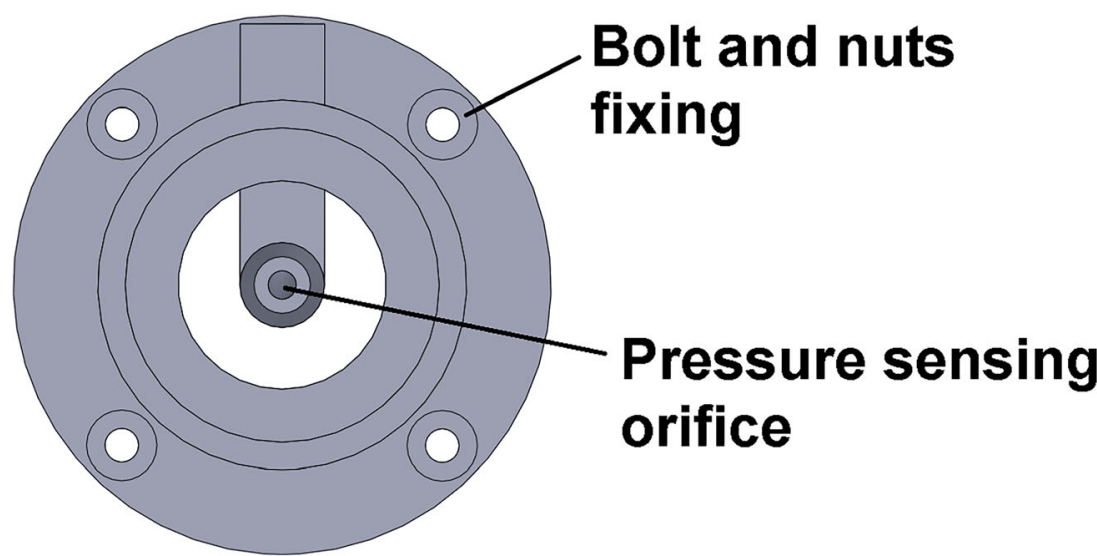


Fig. 3 Transducer mesh model. The mesh set up as tetrahedral for all geometry and extra-fine for all elements generated. This mesh model was simplified due to the symmetry axis

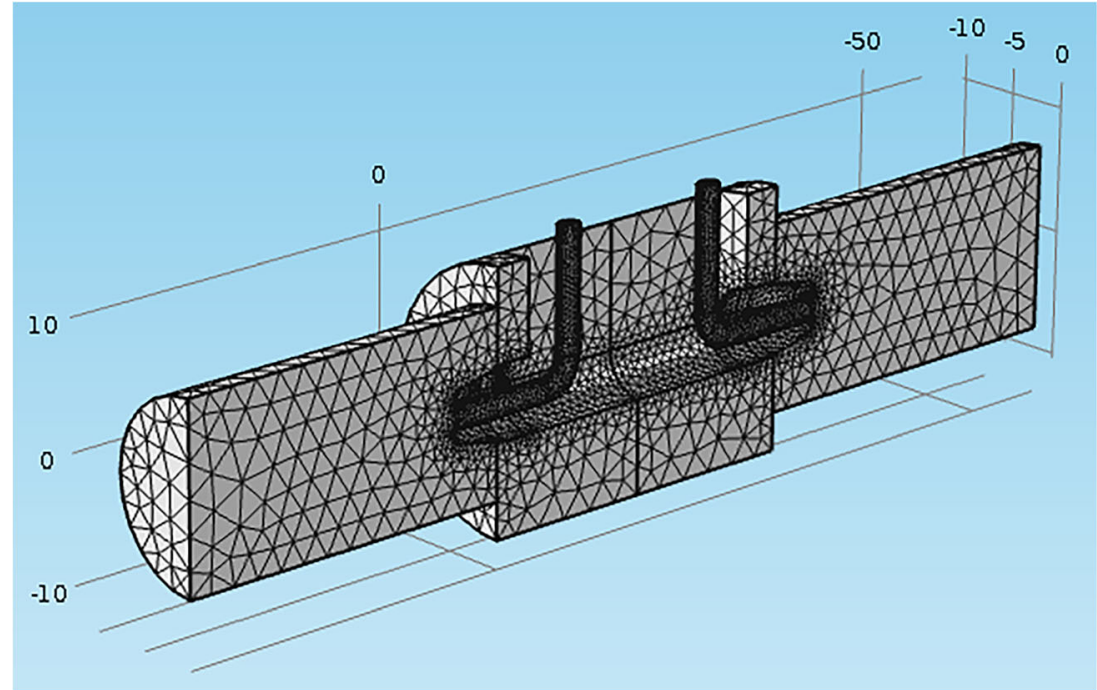

where $P_{\mathrm{AW}}$ is the airway pressure, $T$ is the gas temperature, and $\rho_{0}$ is the density of the gas mixture in standard conditions $\left(T=293.15 \mathrm{~K} ; P_{\mathrm{AW}}=101.3 \mathrm{kPa}\right)($ Meriläinen et al. 1993$)$.

\section{Flow transducer manufacturing by fused deposition modeling}

To fabricate the transducer, we have employed the fused deposition modeling (FDM): a popular AM process in which materials such as acrylonitrile butadiene styrene (ABS), polylactic acid (PLA), and polycarbonates (PC) are melted with different nozzle orifice diameters providing resistance and resolution to the fabricated object.

The stereolithography (STL) file was generated from the CAD model to provide correct print data to the AM fabrication machine (Jyothish Kumar et al. 2018). The open-source software Cura (Ultimaker 2020) was used to convert the SolidWorks stereolithography (STL) file to a G-code file, which properly orients the printer to print the part and some holding structures that help to print (like the brim lines that augment the part adhesion to the heat bed). Both the STL model and the G-code model are shown in Fig. 4. The following printing parameters were used to ensure the desired quality: $20 \%$ of infill, brim hot plate adhesion with 13 lines, and extrusion temperature of $513.15 \mathrm{~K}\left(240{ }^{\circ} \mathrm{C}\right)$. The extrusion temperature is critical and its drop during the FDM process might cause nonuniformity in printing, weakening the mechanical structure (Ngo et al. 2018).

The transducer parts were then produced using ABS filaments and a FDM printer (Anycubic Delta, Anycubic 2020) which uses the Kossel open-source system. To achieve the desired quality, a printer nozzle with a diameter of $0.4 \mathrm{~mm}$ was chosen and the resolution of the axial printer steps was set to $0.1 \mathrm{~mm}$. This is the best possible resolution with this printer and it was chosen to avoid the staircase effect and the interlayer gaps, which contribute to the failure of the printed part (Wickramasinghe et al. 2020). After printing, the existence of defects in the printed parts was verified through visual inspection as suggested by Armillotta (2006), searching for gaps between layers and verifying if the surfaces of the parts are smooth.

\section{Results}

In Fig. 5, it is possible to see the velocity profile calculated for an inlet flow of $1.67 \cdot 10^{-3} \mathrm{~m}^{3} / \mathrm{s}(100 \mathrm{~L} / \mathrm{min})$. In the pressure sensing lines and close to the walls, the velocity is 0 , as expected, and the inlet flow exhibits a higher velocity area near the point where it strikes the sensing tip (about $60 \mathrm{~m} / \mathrm{s}$ ). Beyond this point, the velocity accommodates in such a way that the air flows beside the tip and continues until the formation of the outlet flow.

For the same inlet flow shown in Fig. 5, the pressure profile (Fig. 6) indicates that the pressure is higher where the airflow strikes the inlet sensing tip $(1.62 \mathrm{kPa})$ due to the change in the flow's direction. The velocity accommodates in such a way that the pressure near the outlet sensing tip gradually decreases while the flow leaves the transducer. Note that the pressure is constant and stable inside the pressure lines, which is an important characteristic for pressure transducers.

With the model proper setup, a series of simulations was made to estimate the relation between the differential pressure (dP) and the applied flow. The range of simulated flow values was $1.66 \cdot 10^{-7}$ to $5 \cdot 10^{-3} \mathrm{~m}^{3} / \mathrm{s}(0.01$ to $300 \mathrm{~L} / \mathrm{min})$, and it was chosen according to the specifications of a commercially available gas flow analyzer (Fluke 2018). At the minimal and maximal flow values, the $\mathrm{dP}$ delivered by the transducer were $6.535 \cdot 10^{-4} \mathrm{~Pa}$ and $13.178 \cdot 10^{3} \mathrm{~Pa}$, respectively. Inside 
Fig. 4 Transducer STL model (a) and G-code model (b). Blue lines represent the adhesion support and red lines the nozzle print way of the part to be extruded

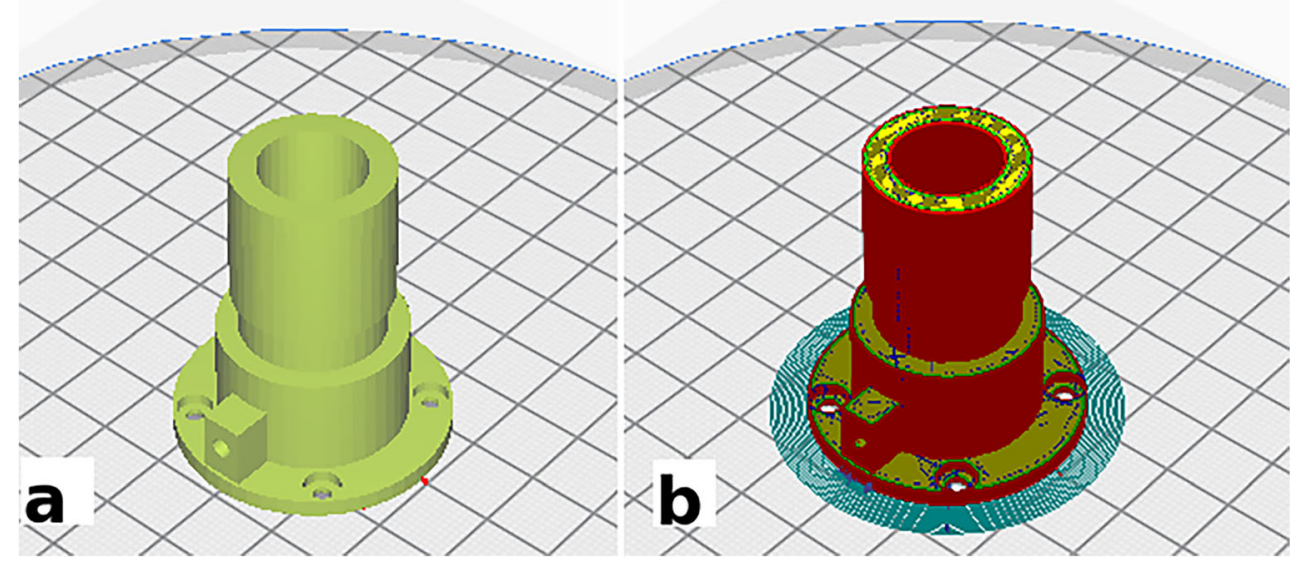

the simulated range, the $\mathrm{dP}$ and the input flow exhibited a quadratic relation, as expected (Fig. 7).

Using the simulated pressure values, it was possible to determine various discharge coefficients related to the applied flows. Plugging the calculated pressure deltas in Eq. (7), it was possible to obtain the discharge coefficients. The channel area $\left(A_{\mathrm{c}}=114.74 \mathrm{~mm}^{2}\right)$ was calculated using the SolidWorks function for calculating the area during transducer design. The coefficient found is $C_{\mathrm{d}}=0.2847$ for an inlet flow of $5 \cdot 10^{-4} \mathrm{~m}^{3} / \mathrm{s}$ (or $30 \mathrm{~L} / \mathrm{min}$ ) and a pressure delta of $143.90 \mathrm{~Pa}$. Figure $7 \mathrm{~b}$ shows in red curve $C_{\mathrm{d}}$ values for flows ranging from 1.66. $10^{-7}$ to $5 \cdot 10^{3} \mathrm{~m}^{3} / \mathrm{s}$. For flow values below $1.66 \cdot 10^{-5} \mathrm{~m}^{3} / \mathrm{s}$, it is possible to observe a slight change in the curvature of $C_{\mathrm{d}}$ (this is visualized when delta pressure and $C_{\mathrm{d}}$ curves are compared).

The printing process took $11 \mathrm{~h}$, resulting in the fabricated SPT transducer shown in Fig. 8 already equipped with silicon hoses for connecting the pressure sensors. The G-code file is available in https://github.com/luizkalva/splitpitottube.

\section{Discussion}

Mechanical ventilators must be constantly monitored and evaluated to ensure safety to their users, but calibration analyzers are not always available for clinical engineers, especially in developing countries and during crisis scenarios such as the COVID-19 pandemic. In this paper, we presented a flow transducer that might be useful in developing more accessible ventilator analyzers.

In order to evaluate the transducer developed here, we compared it with others described in the literature (Table 1). Their meant application is different from ours as they are used for patient monitoring and spirometry but they operate in the same flow range, turning the comparison possible. Moreover, we could not find information about the transducers actually used in commercial ventilator analyzers, openly available in the literature.

The transducers listed in Table 1 are based in the same measurement principle as ours, but they differ in their construction and one of them is not a Pitot tube (Augustynek et al. 2012). Meriläinen et al. (1993) describe a spirometry transducer commercially known as the D-Lite sensor, which detects the $\mathrm{dP}$ from the flow restricted in a structure of three baffles in a $120^{\circ}$ symmetric geometry. The transducer of Nukui et al. (2003) is a Pitot tube inserted in the core of the gas discharge channel which detects the $\mathrm{dP}$ between the center of the duct, where the velocity is maximal, and its wall. Similarly, Funaki et al. (2003) insert the Pitot tube in the
Fig. 5 The velocity profile shows where the velocity is 0 : inside sensing lines and close to the walls. The flow velocity near the region where the flow strikes the sensing tip is about $60 \mathrm{~m} / \mathrm{s}$

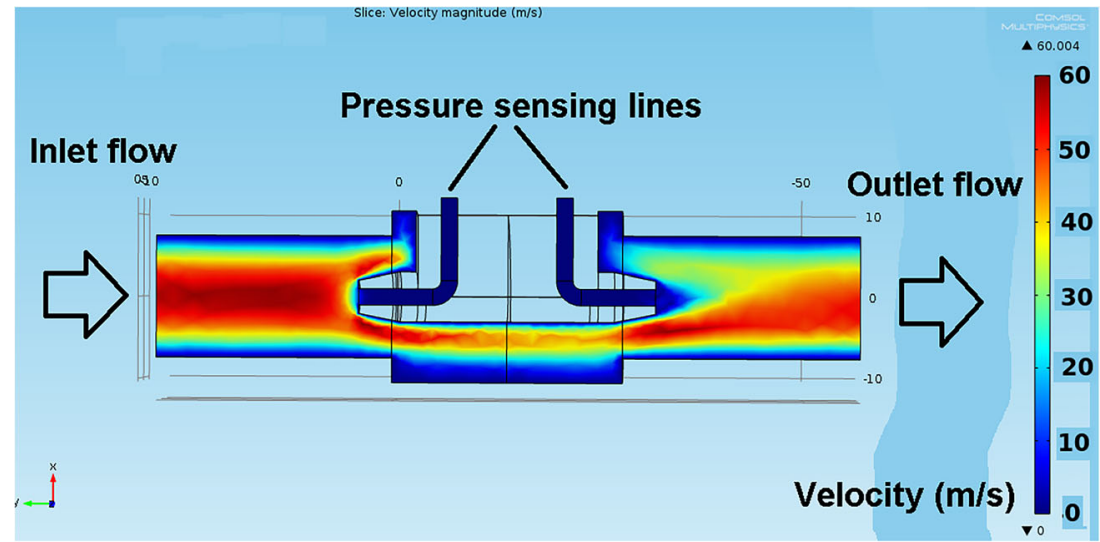


Fig. 6 Pressure profile showing that the pressure is high where the airflow strikes the inlet tip. The pressure near the outlet sensing tip gradually decreases while the flow leaves the transducer. The pressure is constant inside the pressure lines



center of the channel, but the pressure lines are oriented in the direction of the flow and against it. The transducer of Bridgeman et al. (2012) is a confined Pitot tube (CPT) with an elliptically shaped air expansion cavity in the center of the duct, where a suspended disk is inserted. The device measures the dP between the center of the disk and the duct's wall (Bridgeman et al. 2012). Augustynek et al. (2012) measure the $\mathrm{dP}$ between two pressure lines adapted to the inlet and outlet of a high-efficiency particulate absorbing (HEPA) filter which imposes a restriction for the flow.

Our SPT measures dPs between two points along the same line in the center of the duct, similarly to Meriläinen et al. (1993) and Funaki et al. (2003). Nukui et al. (2003) and Bridgeman et al. (2012) measure dPs between one point in the center of flow and other in the duct's wall. Measuring dPs between two points aligned in parallel to the line center of the duct, confers the same sensing characteristic in direct and

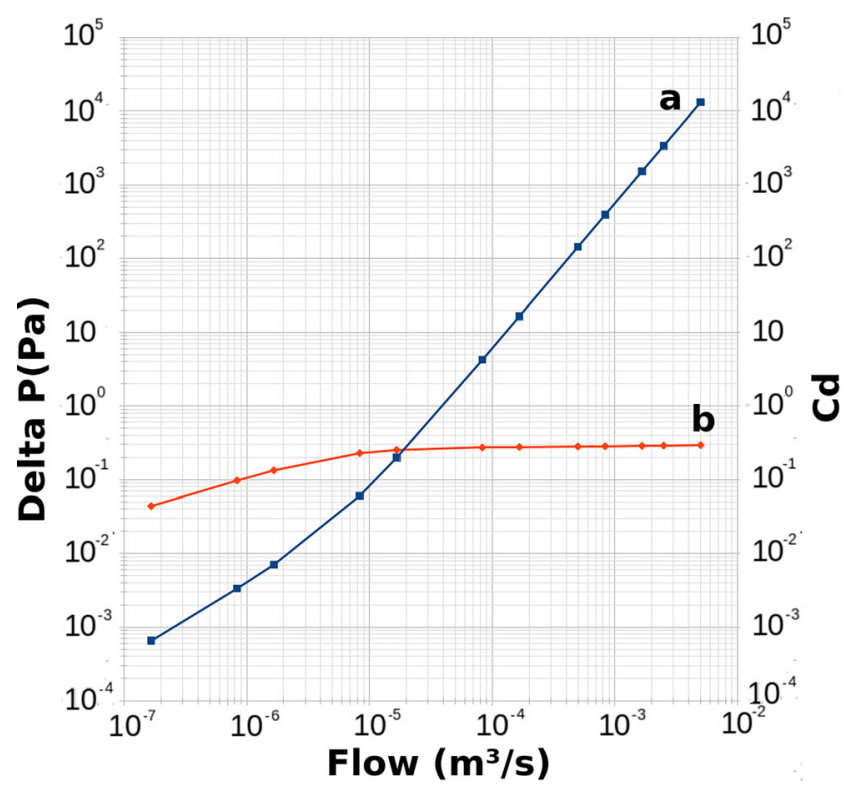

Fig. 7 The blue curve (a) demonstrates a quadratic relationship between the flow and the differential pressure $(\mathrm{dP})$. The red curve (b) shows the discharge coefficient $\left(C_{\mathrm{d}}\right)$ values for the same flow range reverse flows (Meriläinen et al. 1993, Funaki et al. 2003, Augustynek et al. 2012). On the other hand, transducers like the one of Nukui et al. (2003) exhibit different dP behaviors for direct and reverse flows, with backflow showing higher pressure gain compared with forward flow. This asymmetry requires more attention during mounting.

Another structural difference between our transducer and others is the inlet flow diameter, which is larger in some cases (Nukui et al. 2003; Funaki et al. 2003). Larger duct diameters provide less resistance and allow for larger passing flows but yield smaller dP. Therefore, a well-balanced flow transducer allows a dP that is sufficient to be detected with minimum flow resistance. Taking into account the simulation results, we consider that our SPT can deliver sufficient dP to detect passing flows, without offering excessive resistance.

Regarding the fabrication method, only one author employed additive manufacturing like us (Bridgeman et al. 2012). Meriläinen et al. (1993) used plastic mold injection which is an appropriate method to scale production, with low cost per part, but that requires large and expensive machinery. Augustynek et al. (2012) built the transducer by adapting a HEPA filter and thus it depends on a filter provider. Bridgeman et al. (2012) fabricated the transducer using a stereolithography apparatus (SLA) method employing the process of photopolymerization, which is far more expensive that the FDM used here.

Two of the transducers mentioned here were subject to special surface treatment for application in spirometry (Meriläinen et al. 1993; Augustynek et al. 2012). This treatment was necessary because the transducers will be in direct contact with the patient's breathed air. Actually, to be installed in monitoring devices, the transducers require finishing procedures to avoid roughness that facilitates bacterial attachment and corporal fluid deposition with consequent contamination and bacterial growth (Banerjee et al. 2011). The SPT fabricated here with the FDM process presented no mechanical faults but was not submitted to such finishing procedures because it was not devised for patient monitoring and, therefore, will not be in contact with corporal fluids. 
Fig. 8 Front view (a) and side view (b) of the fabricated split Pitot tube transducer (SPT). The silicon hoses were mounted to connect pressure sensors in future developments

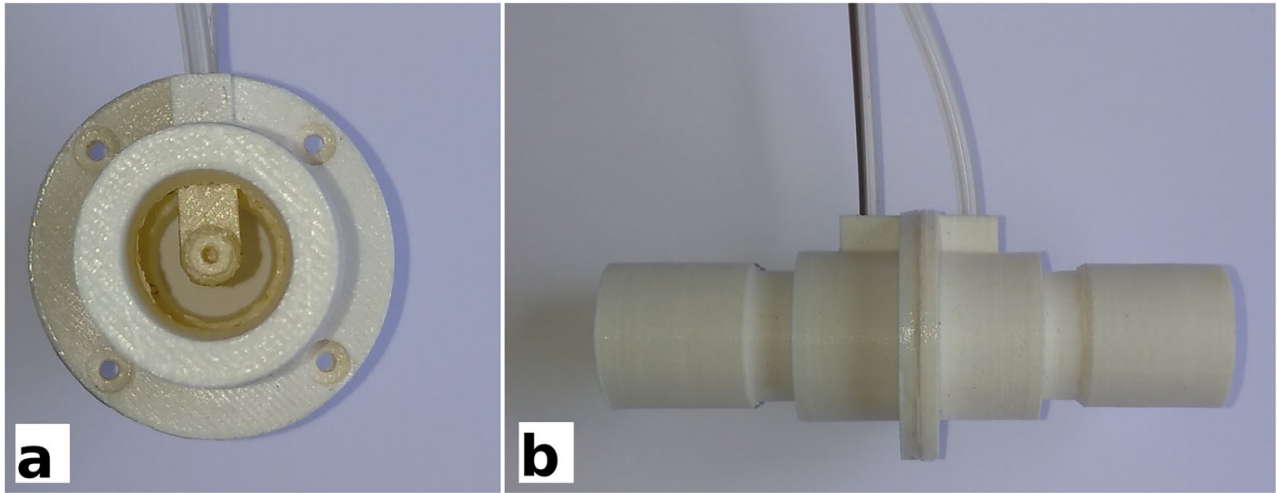

In order to compare the measurement performance of our SPT with the other transducers, we have run simulations to calculate the $\mathrm{dP}$ corresponding to the minimal and maximal input flow values, reported by the authors. The flow values, the $\mathrm{dP}$ reported by the authors and the $\mathrm{dP}$ that would be provided by our transducer, are shown in Table 1. In comparison to most of the references (Meriläinen et al. 1993, Nukui et al. 2003, Funaki et al. 2003 and Augustynek et al. 2012), our SPT exhibited higher $\mathrm{dP}$ values for the same flows. In comparison to ours, the sensor of Augustynek et al. (2012) exhibited the worst performance, certainly because it is the one that does not employ a Pitot tube. The transducer of Bridgeman et al. (2012) is only the one that responds better than ours, but it requires a more complicated design and higher constriction in passing flow. In summary, taking into account the flow measurement range and the comparison with other transducers, one could even consider the possibility of applying this sensor for patient monitoring, if issues related to biohazard were properly addressed.

The main limitation of this article is the absence of bench testes with the fabricated part to verify the validity of the simulated results. However, we believe that providing the simulation data and the G-code for fabrication, this can be performed by anyone with access to the proper equipment.
The intended contribution of this paper was to present the design a flow transducer that can be used to build a ventilator analyzer. In order to obtain the desired flow measurement, though, further developments are necessary. First of all, it is necessary to properly connect pressure sensors to the output of the pressure lines. Then, one needs the proper electronic circuitry and firmware to show the measurement on a display or to send it to a computer. One could use Eq. (7) to obtain the flow from the dP measured with the sensors. There are many options of sensors that could be used such as MPXV7002DP of NXP (NXP 2017) or SDP31 of Sensirion (Sensirion 2017). Before using the transducer in the analyzer, we could compare its measurement with that of rotameter. The whole set, i.e., transducer, sensor, electronic parts, and computer, would provide a more accessible solution than a commercial ventilator analyzer (Fluke 2018), although the last is preferable if one has the means to acquire it. Of course, fabricating the transducer proposed here requires a 3D printer but these machines are becoming popular and, unlike the ventilator analyzers, have a variety of applications in biomedical engineering. Therefore, it is interesting to consider having a FDM printer in the clinical engineering equipment set for fabricating plastic parts, when required.

Table 1 Comparison between the developed SPT and other flow transducers from the literature

\begin{tabular}{|c|c|c|c|c|c|c|}
\hline & $\begin{array}{l}\text { Flow range: } \min \text { to } \max \\
\text { flow }\left(\mathrm{m}^{3} / \mathrm{s}\right)\end{array}$ & $\begin{array}{l}\mathrm{dP} \text { range } \\
(\mathrm{Pa})\end{array}$ & $\begin{array}{l}\text { Inlet flow } \\
\text { diameter (mm) }\end{array}$ & $\begin{array}{l}\text { Our } \mathrm{dP} \text { range for the same } \\
\text { flow range }(\mathrm{Pa})\end{array}$ & $\begin{array}{l}\text { Fabrication } \\
\text { method }\end{array}$ & $\begin{array}{l}\text { Pitot } \\
\text { tube }\end{array}$ \\
\hline Meriläinen et al. (1993) & $\begin{array}{l}2.500 \cdot 10^{-5} \\
1.667 \cdot 10^{-3}\end{array}$ & $\begin{array}{l}1.960 \cdot 10^{-1} \\
5.884 \cdot 10^{2}\end{array}$ & 13 & $\begin{array}{l}4.210 \cdot 10^{-1} \\
1.536 \cdot 10^{3}\end{array}$ & Mold injection & Yes \\
\hline Nukui et al. (2003) & $\begin{array}{l}0 \\
6.667 \cdot 10^{-3}\end{array}$ & $\begin{array}{l}0 \\
\sim 3.250 \cdot 10^{2}\end{array}$ & 20 & $\begin{array}{l}0 \\
2.315 \cdot 10^{4}\end{array}$ & Not informed & Yes \\
\hline Funaki et al. (2003) & $\begin{array}{l}1.667 \cdot 10^{-4} \\
1.667 \cdot 10^{-3}\end{array}$ & $\begin{array}{l}\sim 2.000 \cdot 10^{1} \\
\sim 1.100 \cdot 10^{3}\end{array}$ & 20 & $\begin{array}{l}1.653 \cdot 10^{1} \\
1.537 \cdot 10^{3}\end{array}$ & Not informed & Yes \\
\hline $\begin{array}{l}\text { Bridgeman et al. (2012) with a } \\
\text { disk of } 9.25 \mathrm{~mm}\end{array}$ & $\begin{array}{l}3.333 \cdot 10^{-5} \\
3.333 \cdot 10^{-4}\end{array}$ & $\begin{array}{l}\sim 3.000 \\
\sim 1.350 \cdot 10^{2}\end{array}$ & 10 & $\begin{array}{l}7.263 \cdot 10^{-1} \\
6.466 \cdot 10^{1}\end{array}$ & $\mathrm{AM}$ & Yes \\
\hline Augustynek et al. (2012) & $\begin{array}{l}3.000 \cdot 10^{-4} \\
7.000 \cdot 10^{-4}\end{array}$ & $\begin{array}{l}3.250 \cdot 10^{-2} \\
2.251 \cdot 10^{-1}\end{array}$ & Not informed & $\begin{array}{l}5.254 \cdot 10^{1} \\
2.794 \cdot 10^{2}\end{array}$ & $\begin{array}{l}\text { HEPA filter } \\
\text { adaptation }\end{array}$ & No \\
\hline
\end{tabular}

Max flow and min flow: maximal and minimal flow values simulated or reported in the references. AM additive manufacturing. The symbol " $\sim$ " means that the values are approximated as they were read from a plot in the original paper 


\section{Conclusion}

According to the simulations done, the split Pitot tube transducer developed here has appropriate characteristics for measuring air flows from mechanical ventilators and delivers pressure values compatible with commercial electronic sensors. The AM is viable for fabricating the transducer, and the printing time is considerably low compared to that necessary to order a similar part from a sales representative.

Funding This study was financed in part by the Coordenação de Aperfeiçoamento de Pessoal de Nível Superior - Brasil (CAPES) Finance Code 001

\section{Compliance with ethical standards}

Conflict of interest The authors declare that there is no conflict of interest.

\section{References}

Anycubic. Anycubic Kossel 2020. https:/www.anycubic.com/ collections/kossel-series. Accessed 8 Mar 2020.

Armillotta A. Assessment of surface quality on textured FDM prototypes. Rapid Prototyp J. 2006;12:35-41.

Augustynek M, Adamec O, Micanik D. Using a differential pressure sensor as spirometer. Lect Notes Comput Sci. 2012;7564:236-41.

Badnjevic A, Gurbeta L, Jimenez ER, Iadanza E. Testing of mechanical ventilators and infant incubators in healthcare institutions. Technol Heal Care. 2017;25:237-50

Banerjee I, Pangule RC, Kane RS. Antifouling coatings: recent developments in the design of surfaces that prevent fouling by proteins, bacteria, and marine organisms. Adv Mater. 2011;23:690-718.

Bridgeman D, Tsow F, Xian X, Forzani E. A new differential pressure flow meter for measurement of human breath flow: simulation and experimental investigation Devon. AICHE J. 2012;59:215-28.

Cassidy CJ, Smith A, Arnot-Smith J. Critical incident reports concerning anesthetic equipment: analysis of the UK National Reporting and Learning System (NRLS) data from 2006-2008. Anesthesia. 2011;66:879-88.

COMSOL. COMSOL MULTIPHYSICS. https://www.comsol.com/ comsol-multiphysics. Accessed 22 Jun 2020.

Cooper JB, Newbower RS, Kitz RJ. An analysis of major errors and equipment failures in anesthesia management: considerations for prevention and detection. Anesthesiology. 1984;60:34-42.

Dizon JRC, Espera AH, Chen Q, Advincula RC. Mechanical characterization of 3D-printed polymers. Addit Manuf Elsevier BV. 2018;20: 44-67. https://doi.org/10.1016/j.addma.2017.12.002.

Fluke. VT650 / VT900A gas flow analyzer Users manual. 2018. https:// www.flukebiomedical.com/sites/default/files/resources/vt900a umeng010 0.pdf. Accessed 1 Jun 2020.

Funaki T, Juan Hou, Nukui K, Kawashima K, Fujita T, Kagawa T. Characteristic analysis of dual direction Pitot type flowmeter $2003 ; 1736-1739$
Gibson I, Rosen D, Stucker B. Additive manufacturing technologies: 3D printing, rapid prototyping, and direct digital manufacturing, second edition. Addit. Manuf. Technol. 3D Printing, Rapid Prototyping, Direct Digit. Manuf. Second Ed. 2015. pp. 1-498.

Hossain MA, Rahman AKM, Rahman MR, Islam MR, Ahmad M. Role of clinical engineering to reduce patient's risk factors in life support ventilator. 2nd Int. Conf Electr Inf Commun Technol EICT 2015. 2016;173-7.

Jyothish Kumar L, Pandey PM, Wimpenny DI. 3D printing and additive manufacturing technologies. 3D Print. Addit. Manuf. Technol. Springer Singapore; 2018. https://doi.org/10.1007/978-981-130305-0_14

Khajavi SH, Partanen J, Holmström J. Additive manufacturing in the spare parts supply chain. Comput Ind. 2014;65:50-63.

Martin-Noguerol T, Paulano-Godino F, Menias CO, Luna A. Lessons learned from COVID-19 and 3D printing. Am J Emerg Med. 2020:8-9.

Meriläinen P, Hänninen H, Tuomaala L. A novel sensor for routine continuous spirometry of intubated patients. J Clin Monit. 1993;9:374-80.

Ngo TD, Kashani A, Imbalzano G, Nguyen KTQ, Hui D. Additive manufacturing (3D printing): a review of materials, methods, applications and challenges. Compos. Part B Eng. Elsevier. 2018; https:// doi.org/10.1016/j.compositesb.2018.02.012.

Nukui K, Funaki T, Kawashima K, Kagawa T. A study of characteristics of pitot type flow meter. Proc SICE Annu Conf. 2003;1:846-9.

NXP. MPXV7002 integrated silicon pressure sensor on-chip signal conditioned, temperature compensated and calibrated. Time. Eindhoven; 2017. Available from: https://www.nxp.com. Accessed 4 Nov 2020.

Parker. Manual de O'Ring [Internet]. São Paulo; 1997. Available from: www.parker.com.br. Accessed 4 Nov 2020.

Sensirion. Datasheet SDP3x-digital smallest size enables portable applications Calibrated and temperature compensated. Staefa; 2017. Available from: https://www.sensirion.com. Accessed 4 Nov 2020.

SolidWorks. SolidWorks CAD. 2020. Available from: https://www. solidworks.com. Accessed 8 Mar 2020.

Thorn R, Melling A, Köchner H, Haak R, Husain ZD. Flow measurement. In: Webster JG, editor. Crc Press. Meas. Instrumentation, Sensors Handb. Boca Raton: CRC Press LLC; 1999. p. 2585.

Ultimaker. Cura Software. https://ultimaker.com/learn/ultimaker-cura-43-available-now. Accessed 25 Jun 2020.

Wickramasinghe S, Do T, Tran P. FDM-based 3D printing of polymer and associated composite: a review on mechanical properties, defects and treatments. Polymers (Basel). 2020;12(7):1-42.

Wolf AR, Volgyesi GA. A modified Pitot tube for the accurate measurement of tidal volume in children. Anesthesiology. 1995;31:305-9.

Yeong WY, Chua CK. A quality management framework for implementing additive manufacturing of medical devices. Virtual Phys Prototyp. 2013;8:193-9.

Yoshioka J, Nakane M, Kawamae K. Healthcare technology management (HTM) of mechanical ventilators by clinical engineers. $\mathrm{J}$ Intensive Care. 2014;2:1-2.

Publisher's note Springer Nature remains neutral with regard to jurisdictional claims in published maps and institutional affiliations. 